\title{
Chikungunya virus: The neurology
}

\author{
J. M. K. M urthy \\ The Institute of Neurological Sciences, CARE Hospital, Exbibition Road, Nampally, Hyderabad, India
}

\author{
Address for correspondence: \\ J. M. K. Murthy, \\ Chief of Neurology, \\ The Institute of Neurological Sciences, \\ CARE Hospital, Exhibition Road, \\ Nampally, Hyderabad - 500 001, India. \\ E-mail: jmkmurthy@ satyam.net.in
}

DOI: $10.4103 / 0028-3886.51275$

Chikungunya virus (CHIKV) is an insect-borne virus, of the genus, Alphavirus and the family Togaviridae that is transmitted to humans by virus-carrying Aedes mosquitoes $^{[1]}$ and was first recognized in epidemic form in East Africa in 1952-1953. ${ }^{[2,3]}$ In India CHIKV was first isolated in Calcutta in 1963,,$^{[4]}$ with several reported outbreaks in India since then. The recent 2005 CHIKV epidemic, caused by the central/eastern African genotype, occurred among the populations of Réunion and other Indian Ocean islands, ${ }^{[5,6]}$ and spread to India, where an estimated 1.4 million people were infected ${ }^{[7-9]}$ Comparing the earlier outbreaks, the recent episode was massive, spread at a fast pace to wider areas causing serious economic and social impact. ${ }^{[8]}$

Infection from CHIKV infection typically induces a mild disease in humans, characterized by fever, myalgia, arthralgia, and rash. During the recent epidemic, previously unreported severe forms of CHIKV infection were observed in adults, complicated by multi-organ involvement. ${ }^{[10-15]}$ The maximum estimated incidence of severe CHIKV infection was 34 cases per 200,000 population (less than $0.02 \%){ }^{[13]}$ This epidemic also witnessed the first ever CHIKV associated deaths and mother to child transmission. ${ }^{[5,8,14,15]}$

CHIKV infection was first reported to affect the nervous system in the 1960s; ${ }^{[16]}$ in the early 1970s it was found to be associated with meningoencephalitis, myelitis, and choroiditis. ${ }^{[17]}$ The re-emergence of CHIKV infection in areas with efficient clinical facilities has allowed CHIKV-related neurological disease to be better defined both in adults and children. Various neurological complications described in the recent epidemic include: meningo-encephalitis, meningoencephalo-myeloradiculitis, myeloradiculitis, myelitis, myeloneuropathy, Guillain-Barre' (GB) syndrome, external opthalmoplegia, facial palsy, sensorineural deafness, and optic neuritis. ${ }^{[14,15,18-24]}$ Optic nerve involvement in CHIKV infection included papillitis, retrobulbar neuritis, and neuroretinitis. ${ }^{[20]}$ Encephalitis appears to represent the most common clinical manifestation and occurs either simultaneously or within few days of onset of systemic symptoms, during the period of viremia. A delay of more than two weeks had been reported with other complications like myelitis, GB syndrome, and optic neuritits. ${ }^{[14,20,24]}$

The pathophysiology of human CHIKV infection and the neurological complications associated with the disease has so far remained essentially unknown. Animal experimental studies suggest that the fibroblast is the cell chiefly targeted by CHIKV and this accounts for its tropism for muscles, joint, and skin connective diseases closely resembling the cell/tissue tropism observed in biopsy samples of CHIKV infected humans. These studies also identified two critical factors influencing viral replication: neonatal age and defective type-I interferon (IFN) signaling. ${ }^{[25]}$ In the recent epidemic in the Reunion Island, vertical transmission of CHIKV was seen in the neonates born to the mothers infected with the virus intrapartum. ${ }^{[26]}$ Viral inclusions have been demonstrated in Kupffer cells of liver and myocytes, respectively by Lemant et al. ${ }^{[15]}$ in patients with severe disease, thus proving hepatic and myocardial tropism. Ziegler et al. ${ }^{[27]}$ observed the presence of virus in the leg muscles even after the disappearance of viraemia, which lasted for 6-7 days. 
CHIKV is strongly suspected to have neurotropism but has not been well studied like other neurotropic arboviruses including alphaviruses species, such as Eastren equine encephalitis and Venezuelan equine encephalitis. ${ }^{[28]}$ In the experimental studies, Couderc et al. ${ }^{[25]}$ had showed that CHIKV disseminates to the central nervous system in severe cases, where it specifically targets the choroid plexuses and the leptomeninges. In contrast, microvascular endothelial cells that constitute the blood-brain barrier were not infected. The only pathological study had not shown any evidence for the neurotropism for CHIKV. The pathological changes were more of non-specific of encephalitis. ${ }^{[2]}$ Diffusion weighted (DWI) magnetic resonance imaging (MRI) in adult patients with encephalopathy showed multiple small restricted diffusion lesions. ${ }^{[14,29]}$ Contrast MRI imaging showed meningeal enhancement (unpublished personal observations). ${ }^{[29]}$ The most distinctive MRI abnormalities observed in the course of neonatal chikungunya encephalopathy were exclusively located in the white matter and consisted of areas of reversible diffusion restriction, a pattern classically associated with transient ischemia with cytotoxic edema, ${ }^{[26]}$ that does not imply neuronal death. ${ }^{[30]}$

In patients with CHIKV infection with neurological complications, both adults and children, cerebrospinal fluid (CSF) was positive for real-time polymerase chain reaction (RT-PCR) (which detects the genome of virus particles during an active infection) and $\operatorname{IgM}$ serology (which looks for an immune response to recent infection). ${ }^{[1,15,24,29,31,32]}$ Five of the babies born to mothers infected with the virus intrapartum had CSF RT-PCR positive for CHIKV (mean viral load 184,000 copies/ml of CSF), but normal for chemistry and cytology. ${ }^{[26]}$ One may argue that positive RT-PCR or IgM in CSF could be as the result of contamination with peripheral blood. The detection of a very high level of viral genomes $\left(1.5 \times 10^{[8]}\right.$ copies $/ \mathrm{ml}$ ) in the CSF seven days after symptom onset in a fatal case of CHIKV infection cannot be explained by this argument. ${ }^{[32]}$ In few cases CHIKV has been isolated from the CSF in patients with CHIKV encephalitis. ${ }^{[3]]}$

Thus, there exists some evidence in both neonates and adults CHIKV exhibiting a neurotropism. However, we still need a conclusive proof for the neurotropism of CHIKV in the form demonstration of neuronal inclusion bodies as has been shown in myocytes and Kupffer cells of liver.

\section{References}

1. de Lamballerie X, Leroy E, Charrel RN, Ttsetsarkin K, Higgs S, Gould EA. Chikungunya virus adapts to tiger mosquito via evolutionary convergence: A sign of things to come?. Virol J 2008;5:33.

2. Robinson MC. An epidemic of virus disease in Southern Province, Tanganyika Territory, in 1952-53; I, Clinical features. Trans R Soc
Trop Med Hyg 1955;49:28-32.

3. Lumsden WH. An epidemic of virus disease in Southern Province, Tanganyika Territory, in 1952-53; II, General description and epidemiology. Trans R Soc Trop Med Hyg 1955;49:33-57.

4. Shah KV, Gibbs CJ Jr, Banerjee G. Virological investigation of the epidemic of haemorrhagic fever in Calcutta: Isolation of three strains of Chikungunya virus. Indian J Med Res 1964;52:676-83.

5. Pialoux G, Gauzere BA, Jaureguiberry S, Strobel M. Chikungunya, an epidemic arbovirosis. Lancet Infect Dis 2007;7:319-27.

6. Parola P, de Lamballerie X, Jourdan J, Rovery C, Vaillant V, Minodier $\mathrm{P}, \mathbb{a l}$. Novel chikungunya virus variant in travelers returning from Indian Ocean islands. Emerg Infect Dis 2006;12:1493-9.

7. Yergolkar PN, Tandale BV, Arankalle VA, Sathe PS, Sudeep AB, Gandhe SS, \& al. Chikungunya outbreaks caused by African genotype, India. Emerg Infect Dis 2006;12:1580-3.

8. Mavalankar D, Shastri P, Bandyopadhyay T, Parmar J, Ramani KV. Increased mortality rate associated with chikungunya epidemic, Ahmedabad, India. Emerg Infect Dis 2008;14:412-5.

9. Ravi V. Re-emergence of chikungunya virus in India. Indian J Med Microbiol 2006;24: 83-4.

10. Higgs S. The 2005-2006 chikungunya epidemic in the Indian Ocean. Vector Borne Zoonotic Dis 2006;6:115-6.

11. Ligon BL. Reemergence of an unusual disease: the chikungunya epidemic. Semin Pediatr Infect Dis 2006;17:99-104

12. Cordel H, Quatresous I, Paquet C, Couturier E. Imported cases of chikungunya in metropolitan France, April 2005-February 2006. Euro Surveill 2006;11:E060420,3.

13. Quatresous I. E-alert January chikungunya outbreak in Reunion: A French overseas department. Euro Surviell 2006;11:E060202.1.

14. Wadia RS. A neurotropic virus (chikungunya) and a neuropathic aminoacid (homocysteine). Ann Indian Acad Neurol 2007;10:198-213.

15. Lemant J, Boisson V, Winer A, Thibault L, André H, Tixier F, et al. Serious acute chikungunya virus infection requiring intensive care during the Reunion Island outbreak in 2005-2006. Crit Care Med 2008;36:2536-41.

16. Chatterjee SN, Chakravarti SK, Mitra AC, Sarkar JK. Virological investigation of cases with neurological complications during the outbreak of haemorrhagic fever in Calcutta. J Indian Med Assoc 1965;45:314-6.

17. Mazaud R, Salaun JJ, Montabone H, Goube P, Bazillio R. Acute neurologic and sensorial disorders in dengue and chikungunya fever. Bull Soc Pathol Exot Filiales 1971;64:22-30.

18. Bhavana K, Tyagi I, Kapila RK. Chikungunya virus induced sudden sensorineural hearing loss. Int J Pediatr Otorhinolaryngol 2008;72: 257-9.

19. Lalita P, Rathinam S, Banushree K, Maheshkumar S, Vijaykumar R, Sathe PS. Ocular involvement associated with an epidemic outbreak of Chikungunya virus infection. Am J Ophthalmol 2007;144:552-6.

20. Mittal A, Mittal S, Bharati MJ, Ramakrishnan R, Saravanan S, Sathe PS. Optic neuritis associated with Chikungunya virus infections in south India. Arch Ophthalmol 2007;125:1381-6.

21. Wielanek AC, De Monredon J, El Amrani M, Roger JC, Serveaux JP. Guillain-Barre' syndrome complicating a chikungunya virus infection. Neurology 2007;69:2105-7.

22. Rampal, S Meenaxi S, Meena H. Neurological complications in Chikungunya Fever; J Assoc Phys India 2007;55:765-9.

23. Robin D, Le Seach F, Jaffar-Bandjee MC, Rigou G, Alessandri JL. Neurologic manifestations of pediatric chikungunya infection. J Child Neurol 2008;23:1028-35.

24. Chandak NH, Kashyap RS, Kabra D, Karandikar P, Saha SS, \& al. Neurological complications of Chikungunya virus infection. Neurol India 2009;57:177-80

25. Couderc T, Chrétien F, Schilte C, Disson O, Brigitte M, GuivelBenhassine F, \& al. A mouse model for Chikungunya: Young age and inefficient type-I interferon signalling are risk factors for severe disease. PLos Pathog 2008;4:e29.

26. Gérardin P, Barau G, Michault A, Bintner M, Randrianaivo H, Choker $\mathrm{G}$, $\mathbb{A}$ al. Multidisciplinary prospective study of mother-to-child chikungunya virus infections on the island of La Réunion. PLoS Med 2008;5:e60. 
27. Ziegler SA, Lu L, Amelia PA, Rosa TD, Xiao SY, Tesh RB. An animal model for studying the pathogenesis of Chikungunya virus infection. Am J Trop Med Hyg 2008;79:133-9.

28. O'Leary DR, Kuhn S, Kniss KL, Hinckey AF, Rasmussen AS, Pape WJ, et al. Birth outcomes following West Nile Virus infection of pregnant women in the United States: 2003-2004. Paediatrics 2006;117:537-45.

29. Ganesan K, Diwan A, Shankar SK, Desai SB, Sainani GS, Katrak SM. Chikungunya encephalomyeloradiculitis: Report of 2 cases with neuroimaging and 1 case with autopsy findings. A.JNR Am J Neuroradiol 2008;29:1636-7.

30. Ali M, Safriel Y, Sohi J, Llave A, Weathers S. West Nile virus infection: MR imaging findings in the nervous system. ANNR Am J Neuroradiol 2005;26:289-97.

31. Lewthwaite P, Vasanthapuram R, Osborne JC, Begum A, Plank JL,
Shankar MV, et al. Chikungunva virus and central nervous system infections in children, India. Emerg Infect Dis 2009;15:329-31.

32. Casolari S, Briganti E, Zanotti M, Zauli T, Nicoletti L, Magurano F, \& al. A fatal case of encephalitis associated with Chikungunya virus infection. Scand J Infect Dis 2008;40:995-6.

33. Vanlandingham DL, Tsetsarkin K, Hong C, Klingler K, McElroy KL, Lehane MJ, \& al. Development and characterization of a double subgenomic chikungunya virus infectious clone to express heterologous genes in Aedes aegypti mosquitoes. Insect Biochem Mol Biol 2005;35:1162-70.

Accepted on 06-03-2009

Source of Support: Nil, Conflict of Interest: None declared. 